First Peoples Child \& Family Review

An Interdisciplinary Journal Honouring the Voices, Perspectives, and Knowledges of First Peoples through Research, Critical Analyses, Stories, Standpoints and Media Reviews

\title{
The MacPhail Family Aboriginal Pride Program of Calgary
}

\section{Joanne Pinnow and Shane R. Gauthier}

Volume 6, Number 2, 2011

URI: https://id.erudit.org/iderudit/1068873ar

DOI: https://doi.org/10.7202/1068873ar

See table of contents

\section{Publisher(s)}

First Nations Child and Family Caring Society of Canada

ISSN

1708-489X (print)

2293-6610 (digital)

Explore this journal

Cite this article

Pinnow, J. \& Gauthier, S. (2011). The MacPhail Family Aboriginal Pride Program of Calgary. First Peoples Child \& Family Review, 6(2), 14-19.

https://doi.org/10.7202/1068873ar

\section{Article abstract}

Since 1997, certain schools within Calgary have adopted the MacPhail Aboriginal Pride Program. This pilot program intends "to increase graduation rates among Aboriginal students, which historically have been lower than that of their non-Aboriginal peers. Its approach is based on the premise that students who bond and relate to their school environment are more likely to stay in school and succeed academically" (Calgary United Way, 2010). The Aboriginal population has been growing quickly, and Aboriginal children account for a growing proportion of all of the children in Canada (O'Donnel, 2006, p. 65). However, despite growing numbers, many Aboriginal children who live off reserve are being raised in communities where Aboriginal people represent only a small minority. In these communities, it is difficult to maintain ties to Aboriginal traditions and cultures. The MacPhail Aboriginal Pride Program attempts to help Aboriginal children and youth maintain these cultural ties and helps by infusing Aboriginal history and culture in the curriculum and by encouraging activities such as field trips and presentations. The MacPhail Aboriginal Pride Programs in Calgary strive to "achieve higher graduation rates, have consistent attendance rates, and experience a sense of pride in their culture and a willingness to share their culture with non-aboriginal peers and families."
This document is protected by copyright law. Use of the services of Érudit (including reproduction) is subject to its terms and conditions, which can be viewed online.

https://apropos.erudit.org/en/users/policy-on-use/ 


\title{
First Peoples Child \& Family Review
}

An Interdisciplinary Journal Honoring the Voices, Perspectives and Knowledges of First Peoples through Research, Critical Analyses, Stories, Standpoints and Media Reviews

Volume 6, Number 2, 2011, pp. 14-19

\section{The MacPhail Family Aboriginal Pride Program of Calgary*}

\author{
Joanne Pinnow and Shane R. Gauthier ${ }^{\mathrm{b}}$
}

\author{
a Community Planner, Aboriginal Youth \& Education, United Way of Calgary \\ and area, Calgary, AB, Canada \\ b Consultation Manager, Aboriginal Relations, Government of Alberta, \\ Edmonton, AB, Canada
}

\section{Introduction}

Urban Aboriginal Peoples are considered to be part of a vulnerable population. Vulnerable Aboriginal peoples include:

\begin{abstract}
Individuals and communities that have been affected by the multigenerational impacts of colonialism, such as the effects of residential schools. These effects may include systemic racism and discrimination, resulting in chronic low income, high mobility, loss of culture, and other negative social indicators. Aboriginal peoples include First Nations (status, non-status and Bill C-31 individuals), Métis, and Inuit people. (City of Calgary, 2010)
\end{abstract}

Since 1997, certain schools within Calgary have adopted the MacPhail Family Aboriginal Pride Program. This pilot program intends "to

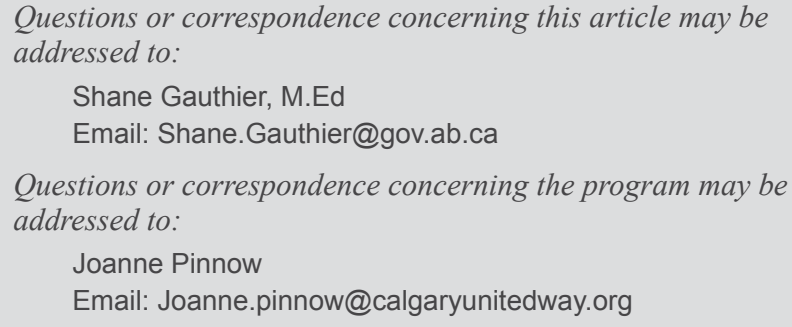

\begin{abstract}
Since 1997, certain schools within Calgary have adopted the MacPhail Aboriginal Pride Program. This pilot program intends "to increase graduation rates among Aboriginal students, which historically have been lower than that of their non-Aboriginal peers. Its approach is based on the premise that students who bond and relate to their school environment are more likely to stay in school and succeed academically" (Calgary United Way, 2010). The Aboriginal population has been growing quickly, and Aboriginal children account for a growing proportion of all of the children in Canada (O'Donnel, 2006, p. 65). However, despite growing numbers, many Aboriginal children who live off reserve are being raised in communities where Aboriginal people represent only a small minority. In these communities, it is difficult to maintain ties to Aboriginal traditions and cultures. The MacPhail Aboriginal Pride Program attempts to help Aboriginal children and youth maintain these cultural ties and helps by infusing $A b-$ original history and culture in the curriculum and by encouraging activities such as field trips and presentations. The MacPhail Aboriginal Pride Programs in Calgary strive to "achieve higher graduation rates, have consistent attendance rates, and experience a sense of pride in their culture and a willingness to share their culture with non-aboriginal peers and families."

Key words: Pilot program, Aboriginal Students, education, academic success, Calgary, cultural curriculum, graduation rates.
\end{abstract}

increase graduation rates among Aboriginal students, which historically have been lower than that of their non-Aboriginal peers. Its approach is based on the premise that students who bond and relate to their school environment are more likely to stay in school and succeed academically" (Calgary United Way, 2010). The Aboriginal population has been growing quickly, and Aboriginal children account for a growing proportion of all of the children in Canada (O’Donnel, 2006, p. 65). However, despite growing numbers, many Aboriginal children who

* United Way of Calgary and Area has partnered with donors Keith and Kathy MacPhail who provided funding for the MacPhail Aboriginal Pride Program 
live off reserve are being raised in communities where Aboriginal people represent only a small minority. In these communities, it is difficult to maintain ties to Aboriginal traditions and cultures (p. 67). The MacPhail Family Aboriginal Pride Program attempts to help Aboriginal children and youth maintain these cultural ties.

Introducing and focusing on Aboriginal culture in the schools is important; it allows Aboriginal students to feel included, gives them a feeling of self-worth, and increases their interest in education. Research reveals that a strong cultural identity increases the likelihood that Aboriginal students will achieve success in the school system: "there is a direct relationship between students' understanding of their culture and role in society and their ability to function comfortably in society and to achieve academic success" (Indian Nations at Risk Task Force, 1991, cited in UWCA, 2007, p. 3).

Throughout the years there have been relatively high drop-out rates and low graduation rates for Aboriginal youth. In fact, in 2003, the "Canada West Foundation report documents a $75 \%$ drop-out rate" (United Way of Calgary and Area [UWCA], 2007, p. 1). $49.87 \%$ of the Aboriginal population in Western Canada who were over 15 and not attending school did not have a high school diploma compared to $31.3 \%$ of the general population (Brunnen, 2003, p. 2). Furthermore, "because of the low high school graduation rates, Aboriginal youth are at higher risk of having lower educational levels, lower income levels, poorer health status, and higher rates of homelessness and substandard housing" (UWCA, 2007, p. 1).

\section{The MacPhail Family Aboriginal Pride Program}

The MacPhail Family Aboriginal Pride Program was first implemented in one school in Calgary in 1997. It was then expanded to eight pilot schools within the public and Catholic school systems. The primary target population is Aboriginal children and youth between kindergarten to grade 12. The specific goals of the program:
1. To develop a network of academic support for Aboriginal students, parents/guardians/ families, and school staff

2. To involve Aboriginal students and their families in school events

3. To engage Aboriginal students in cultural, recreational, and social activities

4. To enhance the creativity and artistic abilities of Aboriginal students

5. To develop and sustain stability in the lives of Aboriginal students in and out of school by working with parents/guardians/families and community resources

6. To create environments which encourage Aboriginal students to work alongside all peers for social and emotional support

7. To increase class attendance among Aboriginal students

8. To provide support and resources for school staff (UWCA, 2007, p. 4)

The MacPhail Family Aboriginal Pride Program strives to assist students to "achieve higher graduation rates, have consistent attendance rates, and experience a sense of pride in their culture and a willingness to share their culture with non-aboriginal peers and families" (Tenove, 2010, p. 18). It offers academic support, empowerment, and cultural teachings within an inclusive respectful environment.

\section{The Cultural Enrichment Model}

The basic theory behind the MacPhail Family Aboriginal Pride Program, as explained by Gray and Pritchard (2010), is that First Nation, Metis and Inuit (FNMI) students receive cultural and academic supports as a way (1) "to reinforce a positive cultural identity," (2) "create a sense of belonging," and (3) "impress feelings of value, connectedness and engagement within the school community," which is intended to produce the ultimate outcome of greater academic success and higher graduation rates (p. 1). In other words, there appears to be a three-step process (see diagram 1). 


\section{The MacPhail Aboriginal Pride Program of Calgary}

Diagram 1.

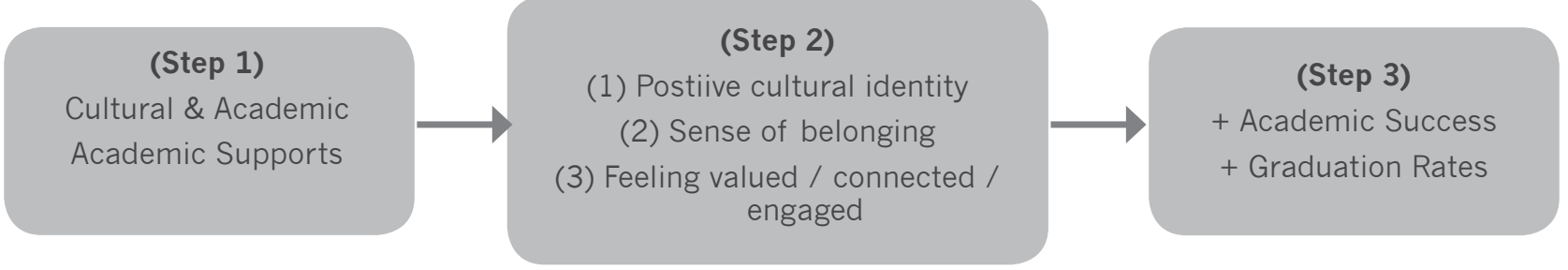

According to this model, we need to have measures of (1), (2), and (3), since this is the critical intermediate objective toward achieving the ultimate outcome. Through accounts of activities, we have strong evidence that cultural and academic support is being given and we can also assess the ultimate outcome by looking at performance indicators such as grades in school and Provincial Achievement Tests (PAT).

The cultural enrichment model of the MacPhail Family Aboriginal Pride Program represents a change in direction from traditional approaches both in its emphasis on the cultural aspects of education and in its recognition that Aboriginal students are only one part of a larger picture that includes parents, teachers, administrators, policy makers, and the community.

\section{Program Theory}

The most effective prevention programs guide program development, assessment, and improvement using theory (Small, Cooney, \& O'Connor, 2009, p. 4). Theory-based programs "have a well thought-out and logical program theory that describes how the program's activities are related to clear, identified, and achievable outcomes" (p. 4). The MacPhail Family Aboriginal Pride Program strives to compliment the school system in order to make it more inclusive and accepting of Aboriginal culture, allowing Aboriginal students to gain a strong sense of identity. It honours Aboriginal knowledge by including traditional Aboriginal activities and by teaching students about Aboriginal history. Nation et al. (2005) argue that "[p]reventative strategies should have a scientific justification or logical rationale" (p. 6). The MacPhail Family Aboriginal Pride Program is a researched based program that theorizes low graduation rates, poor performance, and high drop-out rates could be due to Aboriginal social exclusion; lack of Aboriginal culture and history in the school curriculum, resulting in loss of interest in school subjects; and demoralization. UWCA (2007a) states that research has shown that there is a correlation between cultural inclusion and academic performance (p. 6).

\section{Program's Active Learning Techniques}

Meaningful programs are "more effective when they use active and varied teaching methods that engage participants and enable them to learn and practice new skills" (Small, Cooney, \& O'Connor, 2009, p. 5). Because people tend to learn best when they have opportunities to learn and practice new skills and when they are actively engaged, programs that use various active teaching methods are able to keep participants interested and are more likely to be successful (Small \& Huser, 2010, p. 5). The program engages Aboriginal students by offering various activities and using multiple teaching methods. In addition, "[e]ffective programs have hands-on experiences for participants. Rather than depending solely on sharing information and discussion, effective programs facilitate activities (e.g., role plays, verbal and written practice) that [allow] participants to develop and practice their new skills" (Nation et al., 2005, p. 4).

The MacPhail Family Aboriginal Pride Program's curriculum uses a holistic approach that provides students with different kinds of hands on culturally meaningful experiences. There is a large variety of active instruction including presentations; peer tutoring; Aboriginal pow-wows; afterschool programming; performers; field trips and field experiences; traditional dance, drumming, rolling sage, and beading; and mentoring (UWCA, 2010, 
p. 12-13). The students realize the benefits of the program and recognize that they can do and are doing well in school. They receive help with their school work and many of them actually grew to like school: "They help me with my work: math, science, art, all of them. I like the field trips. My favorite was Head Smashed in Buffalo Jump. In less than a year, the program has changed me. I hated school before. Now I like school and school is more fun. It's a great program!" (Harold, personal communication, May 27, 2010).

Chantel also explains that the MacPhail Family Aboriginal Pride Program has made a huge impact on her life. The program makes a difference:

[B]efore I had a really bad attendance problem. Teachers didn't have time for me. They didn't spend any time with me, but Miss Harper has time for me. She goes to watch my shows/ performances. To her, I can tell this isn't just a job. Because of the program, I miss less school and I don't have a temper any more. In grade 11, people told me that I had a bad temper, but this year I have no temper issues. The biggest thing is that I have someone to talk to. I feel supported when I feel bad. (personal communication, May 27 , 2010)

Chantel also won the Chief David Crowchild Aboriginal Youth Achievement Award. Many of the program participants love the program and have changed their attitudes toward school and learning because of it.

\section{Commitment to Evaluation and Refinement}

The program documents many of its goals, achievements, and strategies. However, "beyond simply documenting their programs, effective programs have staff and administrators who are committed to program monitoring and evaluation" (Small, Cooney, and O'Connor, 2009 , p. 8). In order to learn how well a program is being implemented, if it has any effects on its participants, and how it produces those effects, evaluation is necessary (p. 8).
Within the MacPhail Family Aboriginal Pride Program, there is a commitment to evaluating and refining the program so that it will continue to improve the lives of Aboriginal children in the future. UWCA (2010) states that "[e]valuation of the program needs to be ongoing" (p. 35). In fact, program participants have identified some challenges, including the difficulty in getting parents involved; teachers' concerns about being culturally insensitive; and lack of role clarity for support coordinators. (p. 14). Knowing all of the relevant issues, the program staff are able to make modifications and improve the program. Furthermore, "[a]part from establishing important baseline data to evaluate the success of the program in the future, the program has taken many concrete steps to fulfill the program goals established by the United Way and the Calgary Board of Education" (p. 29).

\section{Developmentally Appropriate \& Socioculturally Relevant}

In order for the program to be effective, it needs to be developmentally appropriate. In other words, it should avoid being too general, and rather respond to specific differences that characterize children/youth of even slightly different ages (Small, Cooney, and O'Connor, 2009 , p. 5). It is important that the program is not administered too early or too late in an individual's development (p. 6). Programs that intervene too early or too late "have greater obstacles to their effectiveness" (p. 6).

The program targets children and youth from kindergarten to grade 12 . Although this is a broad target group, there are different activities geared toward different age groups. Small \& Huser (2010) state, "Tailoring programs and their activities to the particular age or developmental stage of the participants can greatly enhance an intervention's success" (p. 5). By including culturally relevant and age appropriate activities for the children and youth, the MacPhail Family Aboriginal Pride Program is tailored for the participants and has higher rates of success.

Nation et al. (2005) argue that, in order to be socioculturally relevant, programs need to make 
deep structure modifications (p. 9). The MacPhail Family Aboriginal Pride Program is tailored to fit within the socioculturally relevant philosophy of Aboriginal families'. The program is founded on thoughtful research based application that goes deeper by including Aboriginal content in the curriculum, creating a greater awareness of Aboriginal culture and history, and by including culturally relevant activities that acknowledge Aboriginal beliefs and practices. It concentrates on the social and cultural realities that impact the learning of Aboriginal children and youth. Program coordinators are able to devote significant attention to individual student needs.

\section{Implementing the MacPhail Family Aboriginal Pride Program}

\section{Staff}

The quality of the staff that runs a program is one of the most important factors in determining whether a program is effective. "[P]rogram effectiveness is related to the staff's experience, confidence, training, and commitment...Staff members of the most effective programs are able to establish rapport with participants, gain trust, relate well to others, and remain nonjudgmental" (Small, Cooney, and O'Connor, 2009, p. 7). Programs obtain higher retention rates and greater impacts among participants when high staff retention rates are maintained. To that end, staff effectiveness is frequently dependent on receiving support, supervision, ongoing training, and recognition from administrators (Small \& Huser, 2010, p. 7).

Apart from academic credentials, coordinators must have an authentic appreciation of Aboriginal world view. A coordinator at Father Lacombe High School in Calgary, revealed that "[e] xperience working with Aboriginal communities, families, and youth" is essential to become a effective coordinator (personal communication, December 9, 2010). Substantive knowledge of Aboriginal spirituality, urban Aboriginal issues, and the impact of colonization including the profound residential school experience, is key to the program's success.
Minimizing turnover is essential when implementing an effective program. Additionally, Small \& Huser (2010) note that "[b]ehavior change most often happens in the context of positive, supportive relationships where individuals feel safe and trust one another. Effective programs are structured to foster trusting relationships over time among participants, staff, and volunteers" (p. 6). Indeed, "[e]ffective group-based programs pay attention to relationships among participants...good relationships among participants are important for retention because people value the sense of community" (Small, Cooney, and O'Connor, 2009, p. 7). The MacPhail Family Aboriginal Pride Program affords the necessary time to build and strengthen meaningful relationships.

\section{Conclusion}

The MacPhail Family Aboriginal Pride Program's successes demonstrate that it is not only effective but purposeful. Significant improvements in attendance and graduation rates demonstrate it is actualizing the goals set out by the Aboriginal Youth and Education Strategy (UWCA, 2010, p. 32). By integrating Aboriginal culture in the curriculum of Aboriginal learners, they are propelled toward feeling socially accepted and proud of their cultural identities.

"[T]he Aboriginal Pride Program represents a change in direction from traditional linear academic approach both in its emphasis on the cultural aspects of education and in its recognition that Aboriginal students are one part of a larger picture that includes parents, teachers, administrators, policy makers, and the community" (UWCA, 2010, p. 32). The program has had a large amount of success since it has been implemented and the impact of the MacPhail Family Aboriginal Pride Program on Aboriginal students' lives is remarkable. As one of the program participants exclaimed, "This program helped my brother graduate; it's kept me on track-to stay in school and try hard. It makes graduation possible!" (personal communication, June 9, 2011). 
First Peoples Child \& Family Review, Volume 6, Number 2, 2011

\section{References}

Brunnen, B. (2003, December). Encouraging success: Ensuring Aboriginal youth stay in school [Building the New West Project Report \#22]. Calgary, AB: Canada West Foundation.

Calgary United Way. (2010, August). Strong Sense of Self Propels Success. Calgary, AB: Author.

Mendelson, Michael. (2008, July). Improving Education on Reserves: A First Nations Education Authority Act. Ottawa, ON: Caledon Institute of Social Policy.

Nation, Maury et al. (2005, May 12). Applying the Principles of Prevention: What Do Prevention Practitioners Need to Know About What Works? Principles of Effective Prevention Programs. 1-13.

Small, Stephen, and Mary Huser. (2010, January 30). Family-Based Prevention Programs. Manuscript submitted for publication.

Sall, Stephen, Siobhan M. Cooney, and Cailin O'Connor. (2009, February). Evidence-Informed Program Improvement: Using Principles of Effectiveness to Enhance the Quality and Impact of FamilyBased Prevention Programs. Family Relations: Interdisciplinary Journal of Applied Family Studies, 58, $1-13$.

Tenove, Lorianne. (2010). Aboriginal Pride Programs Promote Academic Success. 16-18. Retrieved November 15, 2010 from http://www.casa-acas.ca.

United Way of Calgary and Area (2010, May 9). Progress Report on the Aboriginal Pride Program. Unpublished Manuscript.

United Way of Calgary and Area. (2007). Aboriginal youth and education strategy: Program description and logic model for Aboriginal Pride Program. Calgary, AB: Author. 